\title{
EFFECT OF SURGICAL SYMPATHECTOMY ON THE SENSITIVITY TO EPINEPHRINE OF THE BLOOD VESSELS OF MUSCULAR SEGMENTS OF THE LIMBS ${ }^{1,2}$
}

\author{
BY ROBERT S. DUFF 3
}

\author{
(From the Sherrington School of Physiology, St. Thomas's Hospital, London, England, and \\ the Cardiovascular Laboratory and Department of Internal Medicine, \\ State University of Iowa, Iowa City, Iowa)
}

(Submitted for publication December 19, 1952; accepted May 22, 1953)

Increased sensitivity to epinephrine of blood vessels deprived of their sympathetic nerve supply was first demonstrated in man by Freeman, Smithwick, and White (2). In patients with Raynaud's disease they found that the fall in temperature in the fingers resulting from daily intravenous epinephrine infusions became greater on the eighth to eighteenth day after the limbs had been sympathectomized. The increase in sensitivity was thought to be much greater following postganglionic denervation than after preganglionic decentralization (3). In monkeys, Ascroft (4) estimated that the postganglionic operation caused more than three times as much hypersensitivity as the preganglionic. By contrast Fatherree, Adson, and Allen (5) considered that both operations caused about the same degree of hypersensitivity, which opinion is supported by Duff (6). All these studies were confined to the blood vessels of the skin.

Concerning the effect of sympathectomy on the sensitivity of the blood vessels in skeletal muscle in man, information is incomplete. In a study of the circulatory differences between hands and forearms it was incidentally noted by Grant and Pearson (7) that the dilator response of the forearm to epinephrine was increased in one patient following sympathectomy. In patients with peripheral arterial disease sensitization of the muscle vessels of the lower limb has been reported to follow preganglionic section (8).

In their investigation of the blood flow in human skeletal muscle Allen, Barcroft, and Edholm (9)

\footnotetext{
1 This study was aided in part by a grant from the Medical Research Council of Great Britain.

2 Presented at the Twenty-Fifth Annual Meeting of the Central Society for Clinical Research, Chicago, Illinois, November 7, 1952 (1).

3 Present address: Cardiovascular Laboratory, State University of Iowa Hospitals, Iowa City, Iowa.
}

showed that, during intravenous epinephrine infusions, marked vasodilatation of the forearm occurred early, both in normal and in sympathectomized limbs. Pursuing this study of the effect of epinephrine on muscle blood flow, Duff and Swan (10) reported that during intravenous epinephrine infusions the initial marked dilatation was succeeded by a second phase of moderate dilatation in normal but not in sympathectomized limbs. Because of its absence in chronically sympathectomized limbs this secondary vasodilatation was at that time thought to be an indirect vasomotor effect mediated by the sympathetic nerves. Re-examination of their data in the light of some subsequent critical experiments now reveals that the difference which they found between normal and sympathectomized limbs may be ascribed largely to vascular hypersensitivity in the latter.

In the present paper these additional data are reported, and are incorporated with those of Duff and Swan (10); the whole material being interpreted to provide evidence that hypersensitivity of the vessels of skeletal muscle in the upper and lower limbs may result from pre- and postganglionic sympathectomy in man.

\section{SUBJECTS}

In 15 experiments the blood flow responses to epinephrine in the forearm and calf were measured plethysmographically in five healthy and three sympathectomized subjects additional to the 30 healthy and 13 sympathectomized cases studied by Duff and Swan (10). In the combined group of patients sympathectomy had been performed for Raynaud's disease, hyperhidrosis or causalgia, and one subject had suffered traumatic sympathectomy of one upper limb. The ages of these subjects ranged from 19 to 44 years and none had any evidence of impaired circulation through the muscle of the extremities studied. Tests had been performed to make certain that each sympathectomized limb had complete and effective interruption of the appropriate sympathetic pathway. Failure 
to exhibit vasodilatation or sweating following indirect heating sufficient to raise the body temperature by $1^{\circ} \mathrm{C}$. was taken as good evidence of the absence of vasomotor nerves.

\section{METHODS}

The venous occlusion plethysmograph, which was employed, is based on the principle that brief application of a pressure which occludes the veins but not the arteries of a limb causes congestive swelling of the tissues distally, swelling at a rate exactly equal to that of the arterial inflow (11). The limb to be tested was inserted into a sheath of thin rubber of appropriate size, to either end of which had been sealed stout rubber diaphragms with holes neatly to admit the limb. The limb was adjusted so that the most muscular segment of forearm or calf was enclosed in the rubber sheath. The latter was then placed inside a rigid plastic plethysmograph with the diaphragms in close apposition to its apertures, to the rims of which they were now sealed by screws and gaskets. A segment of forearm or of calf thus lay within the plethysmograph, enclosed in a watertight thin rubber sheath. Inflatable rubber cuffs were applied to the limbs proximal and distal to the plethysmograph, following the general technique of Barcroft and Edholm (12, 13). The plethysmographs were filled with water maintained at $34 \pm 1^{\circ}$ C. (14), care being taken to ensure thorough mixture of the water to obtain a uniform temperature.

The circulation distal to the plethysmograph was excluded, during periods of observation, by inflating the distal cuff at a pressure exceeding the arterial blood pressure. When the proximal cuff was inflated for five to ten seconds at a pressure of 30 to $60 \mathrm{~mm}$. $\mathrm{Hg}$, the consequent swelling of the tissue within the plethysmograph was transmitted to a volume recorder, which was inscribing on a revolving drum. Allowing, between measurements, an interval of at least twice the duration of the venous occlusion, it was possible to obtain records each half minute. From these the forearm or calf blood flow rate was calculated and expressed as $\mathrm{ml}$. blood flow per minute, per $100 \mathrm{ml}$. tissue volume as determined by water displacement.

Throughout each experiment, saline was infused continuously into the basilic vein by means of an electrically driven infusion apparatus delivering $4 \mathrm{ml}$. per minute at a constant rate. After a control period of 20 minutes the plain saline was replaced for exactly 10 minutes with saline containing the requisite amount of synthetic levoepinephrine bitartrate (supplied by British Drug Houses, Ltd.) after which the plain saline infusion was resumed. Records of blood flow and of blood pressure were obtained regularly each half minute throughout both the saline and the epinephrine periods. For all the intravenous studies the amount of epinephrine delivered was $10 \mu \mathrm{g}$. per min. The characteristic symptoms and changes in respiration, heart rate and blood pressure have already been described (10).

In each test the magnitude of the response during each phase was separately assessed. The initial vasodilatation, measured by the highest single value recorded by the plethysmograph during the first phase, was related to the level of flow immediately before the start of the epinephrine infusion. During the second phase the average flow during the last four minutes of the infusion was compared with the average during the last four minutes of the control (pre-epinephrine) period. Since a substantial number of observations relating to this second phase have already been published (10) the further 'results of the present study have not been tabulated, but the combined data have been subjected to statistical analysis and presented in Tables II and III.

\section{RESULTS}

1. Comparison of normally innervated and sympathectomized forearms. The typical findings in a patient with unilateral cervicodorsal sympathectomy, caused by traumatic avulsion of the brachial plexus, are illustrated in Figure 1.

With the first infusion of epinephrine the initial rise in flow on the sympathectomized side reached $15.4 \mathrm{ml}$. per $100 \mathrm{ml}$. per min., or $12.3 \mathrm{ml}$. above the control flow, as compared with a peak of 13.4 $\mathrm{ml}$., or $11.3 \mathrm{ml}$. above control, on the normal side. During the second phase the contrast was more marked. On the normal side the blood flow returned to a level about double the resting rate, but in the sympathectomized forearm the flow returned to, or slightly below, the control level.

In addition to these differences the second epinephrine infusion revealed that the vasodilatation started some one-half minute earlier in the sympathectomized than in the normal forearm. This accelerated response was observed on several occasions in sympathectomized limbs.

2. Comparison of normally innervated and sympathectomized calves. The blood flow in both calves of a young woman who had undergone unilateral lumbar preganglionic sympathectomy one month previously for causalgia of the right foot is charted in Figure 2. On the sympathectomized side the initial vasodilatation occurred one-half minute earlier and reached a peak of $11.8 \mathrm{ml}$., or $9.3 \mathrm{ml}$. above control, as compared with a peak of only $6.8 \mathrm{ml}$. or $4.1 \mathrm{ml}$. above control in the normal limb. During the subsequent phase irregular vasodilatation was present in the normal but not in the sympathectomized calf.

3. Responses of groups of limbs during initial phase. Observations from 29 individuals including 23 of the subjects originally studied by Duff 


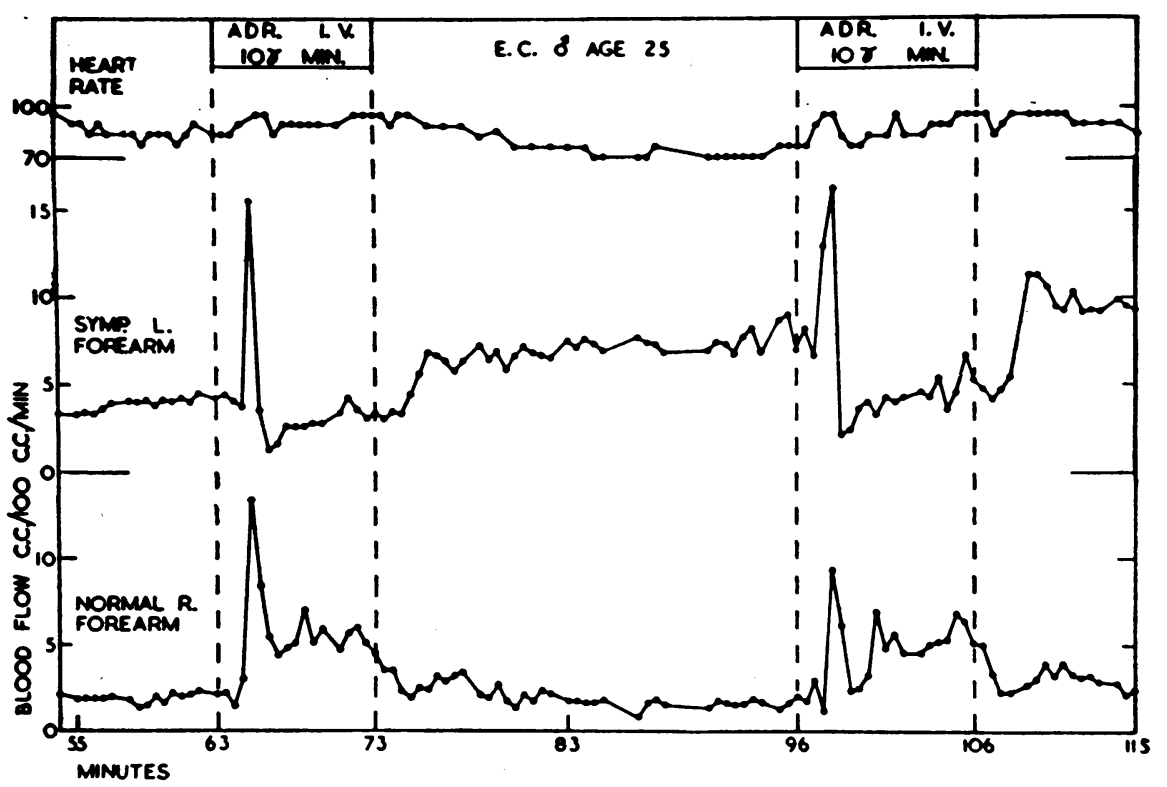

Fig. 1. Blood Flow in Both Forearms of a Patient with a Sympathectomized LEFT UPPER LIMB

The greater initial vasodilatation and subsequent vasoconstriction on the sympathectomized side during intravenous infusions of epinephrine at $10 \mu \mathrm{g}$. per min. are shown.

TABLE I

Maximum rises in blood flow in normal and sympathectomized forearms and calves during first phase of intravenous epinephrine infusions at $10 \mu \mathrm{g}$. per min.

\begin{tabular}{|c|c|c|c|c|c|c|}
\hline \multicolumn{3}{|c|}{ Normal } & & \multicolumn{3}{|c|}{ Sympathectomized } \\
\hline \multicolumn{7}{|c|}{ Blood flow ml. $/ 100 \mathrm{ml} . / \mathrm{min}}$. \\
\hline Control & Peak & $\begin{array}{c}\text { Rise above } \\
\text { control }\end{array}$ & & Control & Peak & $\begin{array}{l}\text { Rise above } \\
\text { control }\end{array}$ \\
\hline $\begin{array}{rr}2.0 \\
2.0 \\
2.1 \\
2.1 \\
2.1 \\
2.1 \\
2.1 \\
2.4 \\
2.7 \\
4.0 \\
4.3 \\
\text { Ave. } 2.6\end{array}$ & $\begin{array}{r}9.3 \\
10.5 \\
7.7 \\
7.3 \\
6.7 \\
13.4 \\
9.4 \\
9.0 \\
7.2 \\
13.0 \\
9.5 \\
9.4\end{array}$ & $\begin{array}{r}7.3 \\
8.5 \\
5.6 \\
5.2 \\
4.6 \\
11.3 \\
6.6 \\
4.5 \\
9.0 \\
5.2 \\
6.8\end{array}$ & Forearms & $\begin{array}{r}1.7 \\
1.9 \\
2.4 \\
2.6 \\
3.1 \\
3.2 \\
4.2 \\
4.2 \\
4.5 \\
4.2 \\
5.2 \\
\text { Ave. } 3.3\end{array}$ & $\begin{array}{r}7.7 \\
13.0 \\
13.3 \\
10.5 \\
15.4 \\
12.0 \\
11.4 \\
15.6 \\
9.2 \\
13.0 \\
12.1\end{array}$ & $\begin{array}{r}6.0 \\
11.1 \\
10.9 \\
7.9 \\
12.3 \\
8.8 \\
7.2 \\
11.4 \\
4.7 \\
7.8 \\
8.8\end{array}$ \\
\hline $\begin{array}{r}2.1 \\
2.3 \\
2.3 \\
2.7 \\
3.4 \\
4.2 \\
4.5 \\
5.2 \\
5.5 \\
5.6 \\
\text { Ave. } 3.8\end{array}$ & $\begin{array}{r}6.1 \\
6.2 \\
5.3 \\
6.8 \\
7.8 \\
10.8 \\
8.1 \\
7.6 \\
11.6 \\
11.4 \\
8.2\end{array}$ & $\begin{array}{l}4.0 \\
3.9 \\
3.0 \\
4.1 \\
4.4 \\
6.6 \\
3.6 \\
2.4 \\
6.1 \\
5.8 \\
4.4\end{array}$ & Calves & $\begin{array}{l}2.2 \\
2.3 \\
2.5 \\
2.6 \\
3.1 \\
4.6 \\
5.4\end{array}$ & $\begin{array}{r}9.3 \\
11.6 \\
11.8 \\
13.2 \\
6.2 \\
12.1 \\
15.4\end{array}$ & $\begin{array}{r}7.1 \\
9.3 \\
9.3 \\
10.6 \\
3.1 \\
7.5 \\
10.0\end{array}$ \\
\hline
\end{tabular}




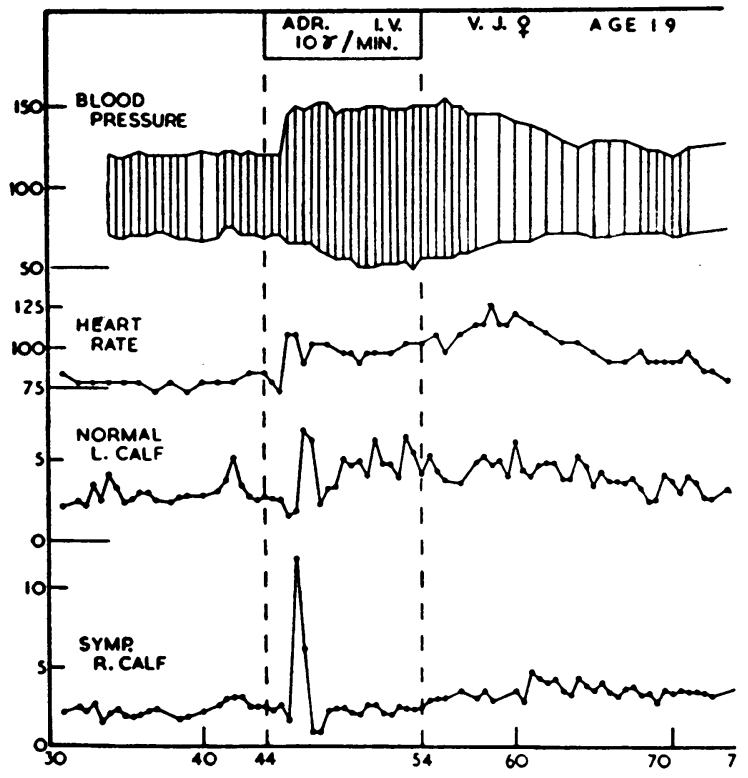

Fig. 2. Arterial Blood Pressure, Heart Rate, and Blood Flow in Both Calves of a Patient Whose Right Lower Limb Was Sympathectomized ONe Month Previously

With the intravenous infusion of epinephrine, the initial vasodilatation is seen to start earlier and reach a higher peak on the sympathectomized side. Some dilatation persists in the normal but not in the sympathectomized calf.

and Swan (10) are presented in Table I. Of the sympathectomized forearms the maximum rise in flow exceeded $10 \mathrm{ml}$. in eight out of ten instances, compared with three out of ten of the normally innervated group.

Likewise, with respect to the calves, the peak flow in five of the seven sympathectomized limbs was greater than $10 \mathrm{ml}$., while in only three of the
TABLE II

Summary of second phase changes in normal and sympathectomized forearms and calves during intravenous infusions of $10 \mu g$. epinephrine per min.*

\begin{tabular}{llll}
\hline \hline & & \multicolumn{2}{c}{ Mean blood flow } \\
\cline { 3 - 4 } No. & Condition & $\mathbf{A}$ B $-\mathbf{A}$ & B-A $\%$ \\
\hline
\end{tabular}

\begin{tabular}{rlrrrr}
\hline \multicolumn{5}{c}{ Forearms } \\
12 & Normal & 2.4 & 5.1 & 2.7 & $122 \%$ \\
11 & Sympathectomized & 4.1 & 4.2 & 0.1 & $17 \%$ \\
\multicolumn{5}{c}{ Calves } \\
15 & Normal & 3.5 & 5.7 & 2.2 & $73 \%$ \\
7 & Sympathectomized & 3.5 & 3.0 & -0.5 & $-12 \%$
\end{tabular}

* A is mean during the four minutes prior to start of epinephrine; $B$ is mean during last four minutes of epinephrine infusions.

ten did flow rise above $10 \mathrm{ml}$. in the normally innervated group.

It is thus apparent that the vasodilatation in forearm and calf at the beginning of intravenous epinephrine infusions was usually greater in the sympathectomized than in the normally innervated limbs.

4. Analysis of group responses during the second phase. The present observations have been added to the larger series of Duff and Swan (10), and summarized in Table II. The mean control blood flow was greater in the sympathectomized than in the normally innervated group of forearms. The difference may be attributed to chance variations of small numbers of observations, but its occurrence made desirable an analysis of the influence of the control rate of blood flow on the response to epinephrine (Table III).

TABLE III

Analyses of linear regression of forearm and calf blood flow during second phase of epinephrine infusions (B), on resting blood flow $(A)^{*}+$

\begin{tabular}{|c|c|c|c|c|}
\hline & $\begin{array}{l}\text { B estimated } \\
\text { to equal: }\end{array}$ & $\begin{array}{l}\text { Significance of } \\
\text { coe.dicient }\end{array}$ & $\begin{array}{l}\text { If } \mathbf{A} \text { is } 3.0 \\
\text { B will be: }\end{array}$ & $\begin{array}{l}\text { Estimated } \\
\frac{B-A}{A} \%\end{array}$ \\
\hline $\begin{array}{l}\text { Forearms: } \\
\text { Normal } \\
\text { Sympathectomized }\end{array}$ & $\begin{array}{l}2.8+.967 \mathrm{~A} \\
2.6+.389 \mathrm{~A}\end{array}$ & $\begin{array}{l}\mathrm{P}<.05 \text { Sig. } \\
\mathrm{P}<.05 \text { Sig. }\end{array}$ & $\begin{array}{l}5.7 \\
3.8\end{array}$ & $\begin{array}{l}90 \% \\
27 \%\end{array}$ \\
\hline $\begin{array}{l}\text { Calves: } \\
\text { Normal } \\
\text { Sympathectomized }\end{array}$ & $\begin{array}{l}2.6+.891 \mathrm{~A} \\
1.2+.510 \mathrm{~A}\end{array}$ & $\begin{array}{l}\mathrm{P}<.05 \text { Sig. } \\
\mathrm{P}<.01 \text { Sig. }\end{array}$ & $\begin{array}{l}5.3 \\
2.7\end{array}$ & $\begin{array}{r}77 \% \\
-10 \%\end{array}$ \\
\hline
\end{tabular}

* A is mean blood flow in $\mathrm{ml} . / 100 \mathrm{ml}$./min. during four minutes prior to start of epinephrine; $\mathrm{B}$ is mean blood flow in $\mathrm{ml} . / 100 \mathrm{ml}$./min. during last four minutes of epinephrine infusions.

$\dagger$ This table shows the behavior of the various groups after adjustment for inequalities of resting blood flow. 
When the blood flow means were adjusted by regression analysis for inequality of the resting values, the difference between normal and sympathectomized forearms during the latter part of the intravenous epinephrine infusions remained statistically significant.

As previously shown (10), during this period (last four minutes of the epinephrine) sympathectomized limbs generally fail to exhibit normal vasodilatation. In the forearms a slight, but not significant, elevation of 17 per cent was present in the sympathectomized group $(t=2.1, P=$ 0.8 ), compared with 122 per cent in the normal group. However, in the sympathectomized calves not merely was the normal second phase of dilatation shown to be absent, but there was actually a small but significant reduction in mean flow $(\mathrm{t}=$ $2.45, \mathrm{P}<0.05)$.

\section{DISCUSSION}

It has been established $(9,10,15,16)$ that the initial vasodilatation in muscular segments of the limbs during infusions of epinephrine results from the direct action of epinephrine on the muscle vessels. The present finding that the magnitude of this initial increase in flow is greater in sympathectomized than in normal limbs is therefore direct evidence that sympathectomy increases the sensitivity of muscle vessels to this action of epinephrine.

The conclusion of Stein, Harpuder, and Byer (8) that hypersensitivity of the calf vessels occurs in limbs sympathectomized by preganglionic section is confirmed. A similar phenomenon is now shown to occur in sympathectomized forearms.

Concerning the second (late) phase of the response of muscle vessels during intravenous epinephrine infusions, it had already been shown that the normal dilatation was reduced or absent in sympathectomized limbs (10). In several sympathectomized individuals the blood flow, especially in the calf, was reduced below the control level, indicating actual vasoconstriction (Table II).

Direct infusions into the brachial and femoral arteries of epinephrine in amounts calculated to be somewhat higher and lower than that distributed through these vessels during intravenous in- fusion of $10 \mu \mathrm{g}$. per min. produce vasodilatation in the forearm and calf only during the first phase $(10,15,17)$. During the second phase the blood flow is either at or slightly below the control level. Increasing the epinephrine concentration in intraarterial infusions tends to cause greater vasoconstriction during this second phase (10).

The sustained moderate vasodilatation in normally innervated forearms and calves during the latter part of the intravenous epinephrine infusions was therefore due to some non-local effect of the epinephrine (10). This could have been produced by the intravenous epinephrine in three ways: $a$ ) elevation of systemic arterial blood pressure; $b$ ) neurogenic sympathetic reflexes; and $c$ ) liberation into the circulation of a vasodilator substance or substances.

The pressor effect of intravenous epinephrine in the concentration of $10 \mu \mathrm{g}$. per min. was shown to be insufficient to account for more than a small proportion of the increased blood flow during this period (10). Whelan's recent demonstration that the second phase of dilatation still occurred in forearms in which the vasomotor nerves were paralyzed by nerve block renders the neurogenic theory untenable (15). He has adduced evidence suggesting that some (as yet unidentified) humoral mechanism may be responsible for the phenomenon (15). If this be so then the inhibition or reversal of the normal second phase dilatation in the sympathectomized limbs can be satisfactorily explained only in terms of an increased sensitivity of the muscle vessels to the direct constrictor action that is normally revealed only by direct intra-arterial infusions of relatively high concentrations of epinephrine. Figures 1 and 2 indicate that in individuals with sympathectomized extremities the systemic dilator mechanism (whether humoral or otherwise) was in operation, for the normally innervated limbs obtained good second phase dilatation.

In respect to the type of operation, all the calves were sympathectomized by preganglionic decentralization, while six of the 11 forearms were sympathectomized by postganglionic denervation. There seems little doubt therefore that preganglionic and postganglionic sympathectomies are both capable of causing hypersensitivity of muscle vessels. Because of the small number of cases, 
valid comparison of the two types of operation was not possible. However, the results do suggest that the degree of sensitization of the mixed group of forearms was no greater (indeed perhaps less) than that of the decentralized calves. Precise elucidation of this matter must await further comparable studies of a larger number of cases.

It has hitherto been assumed (18) that the consistently better clinical results with sympathectomy of lower than of upper limbs were largely due to the reduced liability to hypersensitivity following lumbar sympathectomy, because this operation produces decentralization rather than denervation of the vessels. There is little doubt that the treatment of vasospasm.by surgical sympathectomy is more beneficial in the lower than in the upper limb, but in the opinion of many practising surgeons $(19,20)$ this advantage has not been overcome by adoption of preganglionic operations for the upper limb.

\section{SUMMARY}

1. The initial vasodilatation in the forearm and calf during intravenous infusions of $10 \mu \mathrm{g}$. epinephrine per min. has been shown to be greater in sympathectomized than in normally innervated limbs.

2. Reasons are given for attributing this increase to hypersensitivity of the vessels in muscular segments of the sympathectomized limbs.

3. The reduction or reversal of the normal second phase of vasodilatation in sympathectomized forearms and calves during intravenous epinephrine infusions has been interpreted as further evidence of vascular hypersensitivity in sympathectomized muscles.

4. These phenomena have been shown to occur in limbs sympathectomized either by preganglionic section or by ganglionectomy.

\section{ACKNOWLEDGMENTS}

I am indebted to Prof. H. Barcroft for valuable help and advice, to Dr. H. J. C. Swan who collaborated in obtaining many of the data, and to Dr. J. W. Culbertson and Dr. W. B. Bean for useful criticism. The courtesy of the following surgeons in permitting their patients to be investigated made this study possible: Sir J. Paterson Ross, H. Atkins, Esq., D. W. C. Northfield, Esq., P. Martin, Esq., P. Walker, Esq., and H. Osmond-Clarke,
Esq., C.B.E. My thanks also to the Medical Students of St. Thomas's Hospital, London, who volunteered as subjects; and to the technical and secretarial staff of the Sherrington School of Physiology, London, and the Department of Internal Medicine of the State. University of Iowa.

\section{REFERENCES}

1. Duff, R. S., Supersensitivity of the blood vessels of human skeletal muscle to adrenaline following sympathectomy. J. Lab. \& Clin. Med., 1952, 40, 794.

2. Freeman, N. E., Smithwick, R. H., and White, J. C. with the collaboration of Cannon, B., and Heyl, H., Adrenal secretion in man. The reactions of the blood vessels of the human extremity, sensitized by sympathectomy, to adrenalin and to adrenal secretion resulting from insulin hypoglycemia. Am. J. Physiol., 1934, 107, 529.

3. White, J. C., Okelberry, A. M., and Whitelaw, G. P., Vasomotor tonus of the denervated artery. Control of sympathectomized blood vessels by sympathomimetic hormones and its relation to the surgical treatment of patients with Raynaud's disease. Arch. Neurol. \& Psychiat., 1936, 36, 1251.

4. Ascroft, P. B., The basis of treatment of vasospastic states of the extremities: an experimental analysis in monkeys. Brit. J. Surg., 1937, 24, 787.

5. Fatherree, T. J., Adson, A. W., and Allen, E. V., The vasoconstrictor action of epinephrine on the digital arterioles of man before and after sympathectomy. Surgery, 1940, 7, 75.

6. Duff, R. S., Effect of sympathectomy on the response to adrenaline of the blood vessels of the skin in man. J. Physiol., 1952, 117, 415.

7. Grant, R. T., and Pearson, R. S. B., The blood circulation in the human limb; observations on the differences between the proximal and distal parts and remarks on the regulation of body temperature. Clin. Sc., 1938, 3, 119.

8. Stein, I. D., Harpuder, K., and Byer, J., Reactivity of blood vessels in the sympathectomized human leg. Am. J. Physiol., 1949, 158, 319.

9. Allen, W. J., Barcroft, H., and Edholm, O. G., On the action of adrenaline on the blood vessels in human skeletal muscle. J. Physiol., 1946, 105, 255.

10. Duff, R. S., and Swan, H. J. C., Further observations on the effect of adrenaline on the blood flow through human skeletal muscle. J. Physiol., 1951, 114, 41.

11. Hewlett, A. W., and van Zwaluwenburg, J. G., The rate of blood flow in the arm. Heart, 1909, 1, 87.

12. Barcroft, H., and Edholm, O. G., The effect of temperature on blood flow and deep temperature in the human forearm. J. Physiol., 1943, 102, 5.

13. Barcroft, H., and Edholm, O. G., On the vasodilatation in human skeletal muscle during post-haemorrhagic fainting. J. Physiol., 1945, 104, 161. 
14. Barcroft, H., and Edholm, O. G., Temperature and blood flow in the human forearm. J. Physiol., 1946, 104, 366.

15. Whelan, R. F., Vasodilatation in human skeletal muscle during adrenaline infusions. J. Physiol., 1952, 118, 575.

16. Wilkins, R. W., and Eichna, L. W., Blood flow to the forearm and calf. I. Vasomotor reactions: rôle of the sympathetic nervous system. Bull. Johns Hopkins Hosp., 1941, 68, 425.
17. Duff, R. S., Unpublished observations. Sherrington School of Physiology, London, 1951.

18. Simmons, H. T., and Sheehan, D., The causes of relapse following sympathectomy of the arm. Brit. J. Surg., 1939, 27, 234.

19. Haxton, H. A., Regeneration after sympathectomy and its effects on Raynaud's disease. Brit. J. Surg., 1947, 35, 69.

20. Learmonth, Sir J., The surgery of the sympathetic nervous system. Lancet, 1950, 2, 505. 